\title{
Granite stone subjected to ultrasonic fatigue tests under three point bending loading
}

\author{
Dominguez Alexiane \\ Université Paris-Sud 11, URF Sciences et Techniques, BCST: Biologie Chimie Sciences de la Terre, 15 Rue Georges Clemenceau, \\ 91400 Orsay, France. \\ alexiane.dominguez@u-psud.fr
}

Gonzalo Mariano Dominguez Almaraz, Necker J. Trujillo Alonso

University of Michoacán (UMSNH), Santiago Tapia No. 403, Col. Centro, 58000, Morelia, Michoacán, Mexico

dalmara:@umich.mx.bttp://orcid.org/0000-0002-8786-8640

ingneck.92@gmail.com

\begin{abstract}
Ultrasonic fatigue tests are carried out under the modality of three point bending on the granite stone. The testing specimens present a prismatic shape with the dimensions: $12 \times 3 \times 0.8$ centimeters, in order to be supported by its two ends, and to configure the three point bending modality. Granite specimens are supported on an acrylic structure destined to fix and immobilize the specimens. Vibrating load is applied at the center of testing specimens by a self-designed and fabricated aluminum alloy awl, whose dimensions have been obtained by modal numerical analysis to fit the resonance condition, necessary for the ultrasonic fatigue tests.

Experimental results are obtained at room temperature and humidity between 65 and $75 \%$. The fatigue endurance is determined on the granite under this modality of loading, and the fracture surfaces are analyzed to identify the principal trends related to crack initiation and propagation on this material.

KEYWORDS. Granite stone; Three point bending; Ultrasonic loading; Fatigue endurance; Fracture surfaces.
\end{abstract}

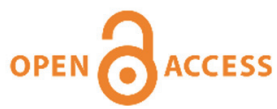

Citation: Alexiane, D., Dominguez Almaraz G.M., Trujillo Alonso N.J., Granite stone subjected to ultrasonic fatigue tests under three point bending loading, Frattura ed Integrità Strutturale, 48 (2019) 70-76.

Received: 30.11 .2018

Accepted: 21.01.2019

Published: 01.04.2019

Copyright: (C) 2019 This is an open access article under the terms of the CC-BY 4.0, which permits unrestricted use, distribution, and reproduction in any medium, provided the original author and source are credited.

\section{INTRODUCTION}

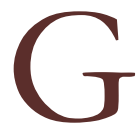
ranite stone has been studied insensibly under compression loading in the last decades [1-6]; nevertheless, few studies have been devoted under tension or bending condition [7-10]. Granite stone profiles are commonly used as structural elements for the house interiors and can undergo tension and bending loading during normal use or under geological phenomena, such as earthquakes [11-14]. 
In this work ultrasonic fatigue tests on the granite stone under three point bending are carried out. Prismatic granite specimens with the dimensions: 12 × 3 × 0.8 centimeters were manufactured and its ends were supported on a selfconstructed acrylic structure to configure the three point bending loading. A self-designed and manufactured aluminum awl, which vibrates under resonance with the ultrasonic machine, was applied at the center of specimen [15]. The initial pressure of the awl at the center of granite specimens is a key experimental parameter for the ultrasonic endurance results under this modality of loading. All tests were carried out at room temperature $\left(20-22^{\circ} \mathrm{C}\right)$, and with an environmental humidity between 65 and $75 \%$. In addition, thermography piectures were taken during experimental testing to register the temperature evolution of the specimen.

\section{EXPERIMENTAL CAMPAIGN}

\section{Ultrasonic fatigue tests}

7 he dimensions (mm) of the granite specimens are shown in Fig. 1(a), whereas the self-designed and manufactured acrylic structure destined to fix and attach the testing specimens is presented in Fig. 1(b). The acrylic structure allows transmitting motion to the granite specimen with the aid of an endless screw.
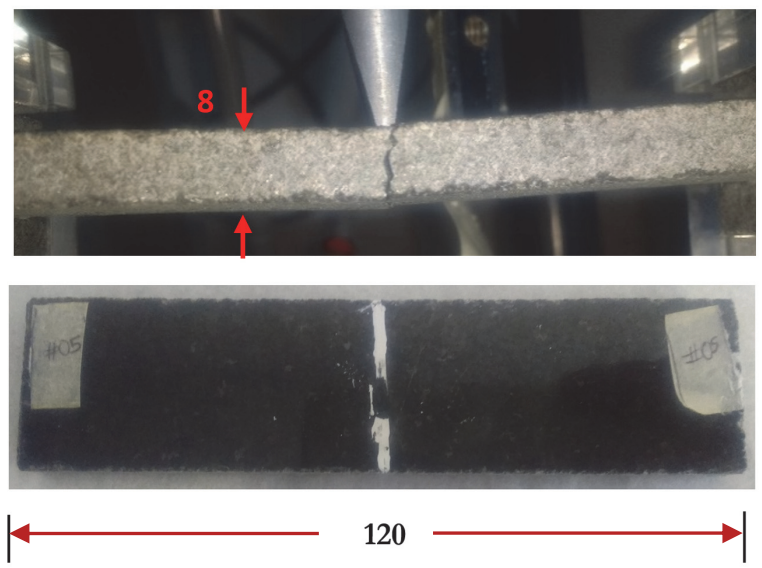

(a)

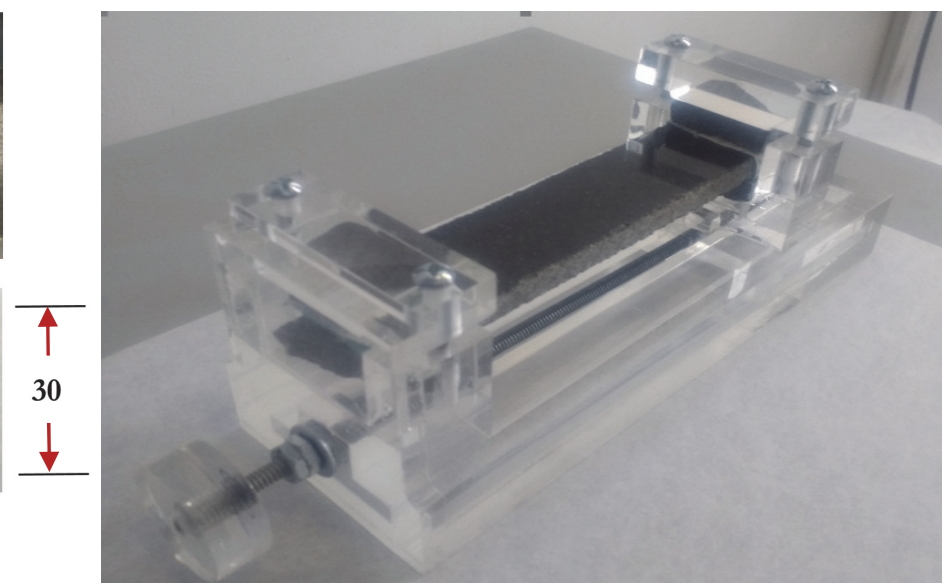

(b)

Figure 1: (a) Dimension (mm) of granite specimen, (b) Self designed and constructed acrylic structure to support the specimen.

The self-designed awl used to apply the vibrating load to the granite prism was manufactured from the aluminum alloy AISI 7075-T6. The resonance condition with the ultrasonic machine was achieved by modal finite element analysis, using the Block Lanczos extraction method and the 20NODE Solid 95 element, in Ansys 16.2 software. As shown in Fig. 2(a): the natural frequency of vibration along the awl is $20060 \mathrm{~Hz}$, a value very close to the ultrasonic vibration of the source: 20000 Hz. In Fig. 2(b) is illustrated the attachment of the awl to the ultrasonic fatigue machine, and the granite specimen supported by the acrylic structure (a thicker specimen used for calibration before the experimental tests).

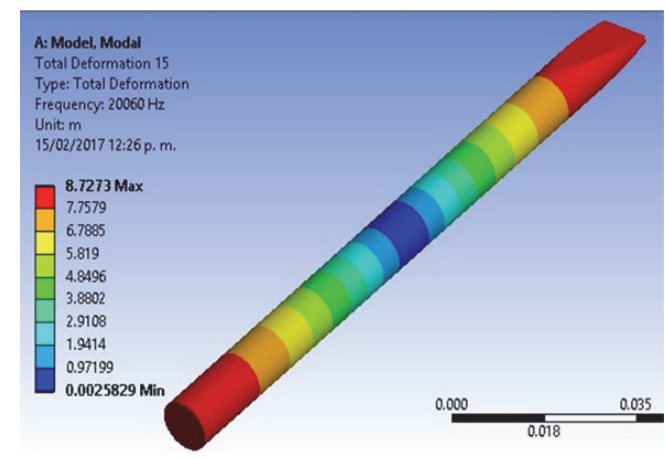

(a)

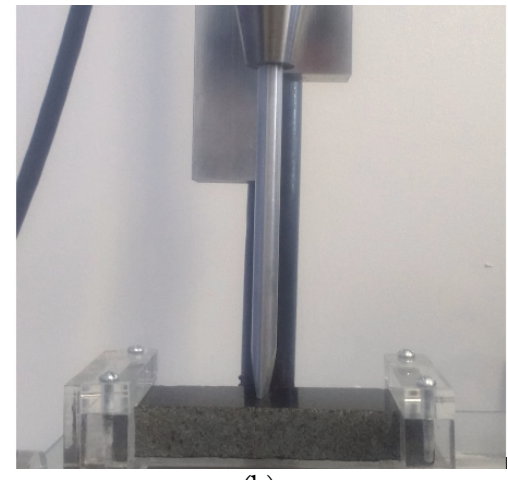

(b)

Figure 2: (a) Modal analysis for the natural frequency of the awl, (b) Awl attached to ultrasonic machine and image of the specimen. 
An initial pressure was applied to the granite specimens before performing the ultrasonic fatigue tests in order to keep the contact between the awl and the specimen surface when the ultrasonic vibration was applied. The initial applied pressure, Fig. 3(a), was fixed to $9.5 \mathrm{MPa}$ approximately (corresponding to $20 \mu \mathrm{m}$ of flexion at the contact line between the awl and the specimen surface), for all the experimental tests. The pressure is deduced by numerical analysis: imposing a displacement at the center of the clamped granite specimen and obtaining the corresponding stress. The displacement was measured physically by a laser proximity sensor with the precision of $\pm 1.5 \mu \mathrm{m}$. Three amplitudes of ultrasonic vibration from the initial pressure with fully reversed stress $(\mathrm{R}=-1)$, are imposed on the granite specimens: 13, 18 and $20 \mu \mathrm{m}$. Fig. 3(b) presents the temperature distribution taken by thermographic camera at the beginning of ultrasonic tests under three point bending. Environmental temperature was between 20 and $23^{\circ} \mathrm{C}$; whereas the highest temperature at the end of test attained $65-70^{\circ}$ C.

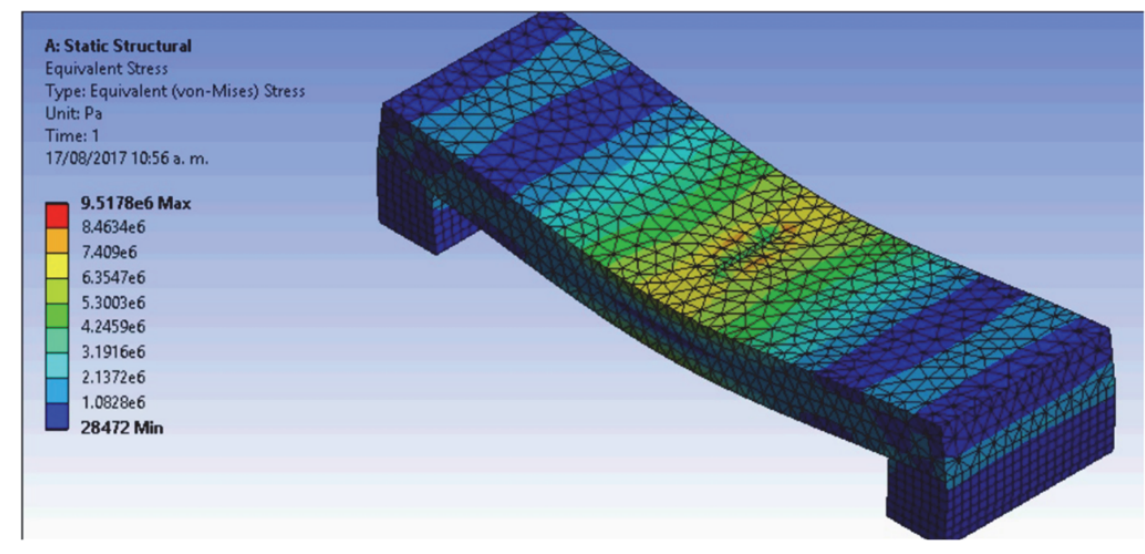

(a)

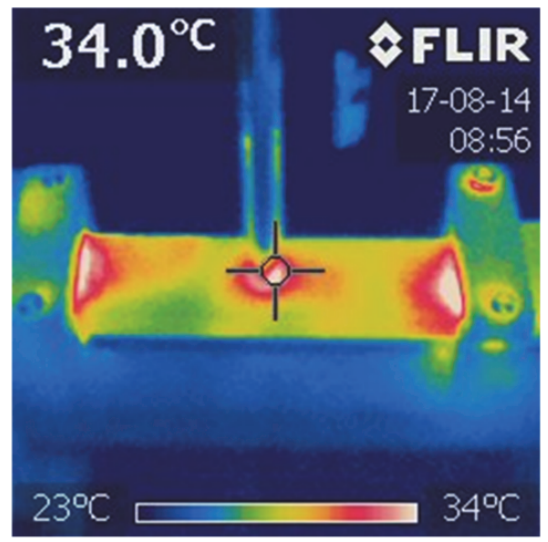

(b)

Figure 3: (a) Initial pressure applied by the awl to the center of specimen, before ultrasonic tests, (b) Temperature recorded by thermographic camera at the beginning of ultrasonic tests.

Fatigue behavior results were obtained for the granite specimens based on the experimental tests. Fig. 4 shows the experimental results with fully reversed stress and $20 \mu \mathrm{m}$ of ultrasonic vibration (each dot in the graph represents the average of three experimental tests), where the vertical axis is the maximum stress applied at the center of granite specimen and the horizontal axis is the number of cycles of fatigue life.

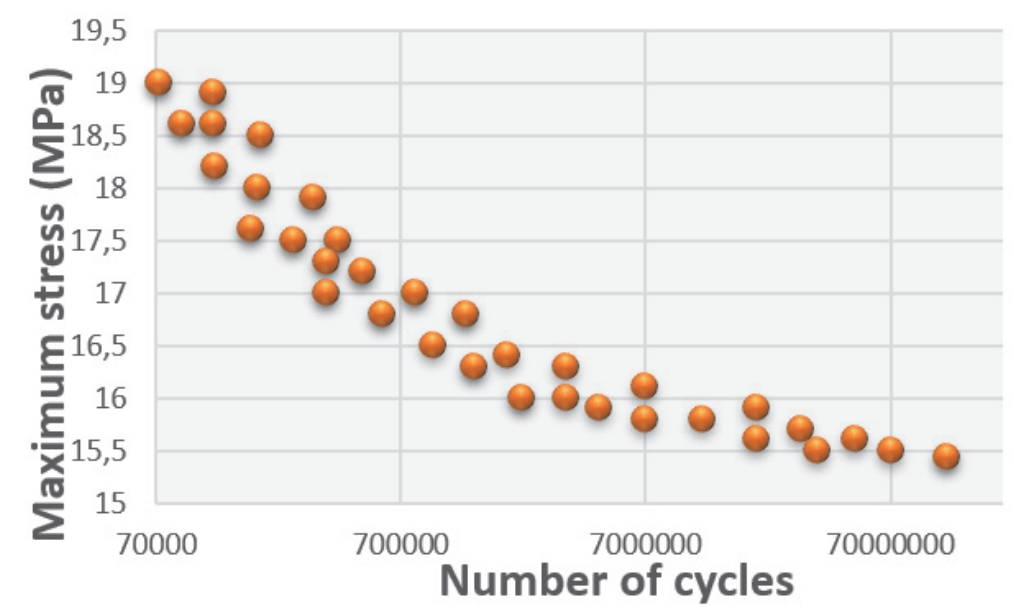

Figure 4: Ultrasonic fatigue endurance of granite stone under three point bending.

In Fig. 5, the temperature variation of a granite prism specimen during ultrasonic testing at high load level is shown (close to $19 \mathrm{MPa}$, Fig. 4). 


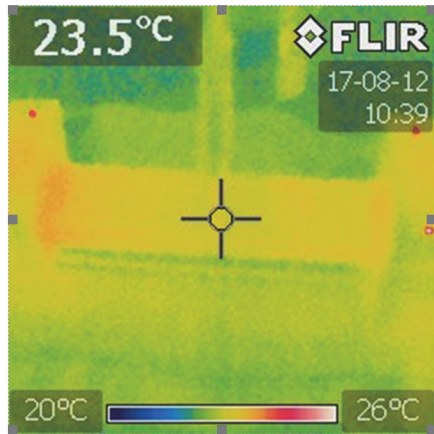

(a)

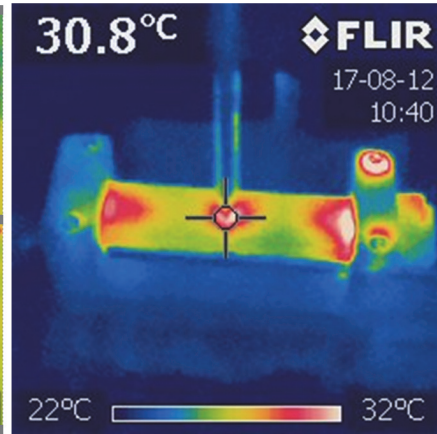

(b)

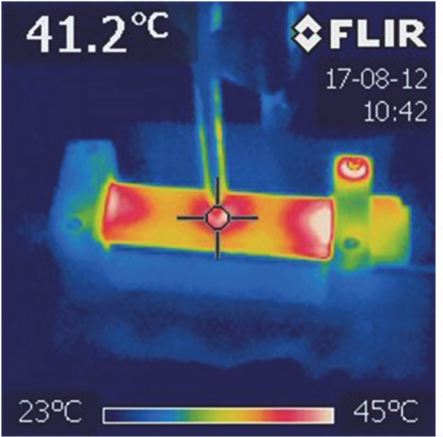

(c)

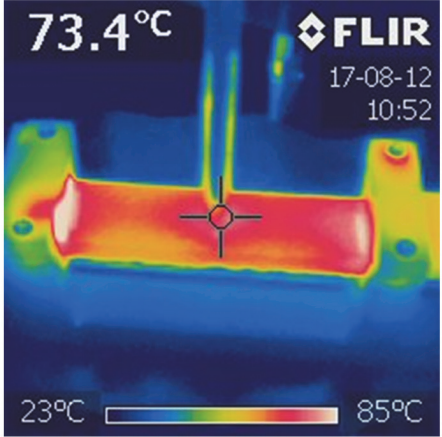

(d)

Figure 5: (a) Temperature before ultrasonic testing, (b) after 2 seconds of ultrasonic test, (c) after 4 seconds of ultrasonic test, (d) at fracture of granite specimen (after 15 seconds, approximately).

Temperature during ultrasonic fatigue tests seems to be concentrated for the first seconds at the center of specimen (where the awl is applied) and at the specimen extremes, Fig. 5(b) and 5(c); afterwards, it is uniformed along the specimen with higher values at the extremes just before fracture, as shown in Fig. 5(d).

About the crack behavior under this modality of loading, in Fig. 6(a) and 6(b) the fracture surfaces are illustrated for the lower (15.5 MPa) and higher (19 MPa) loading, respectively.

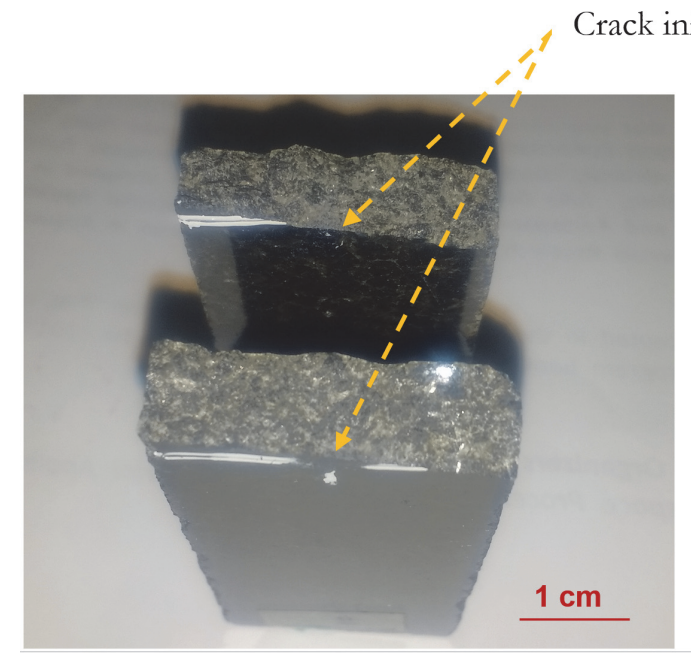

(a)

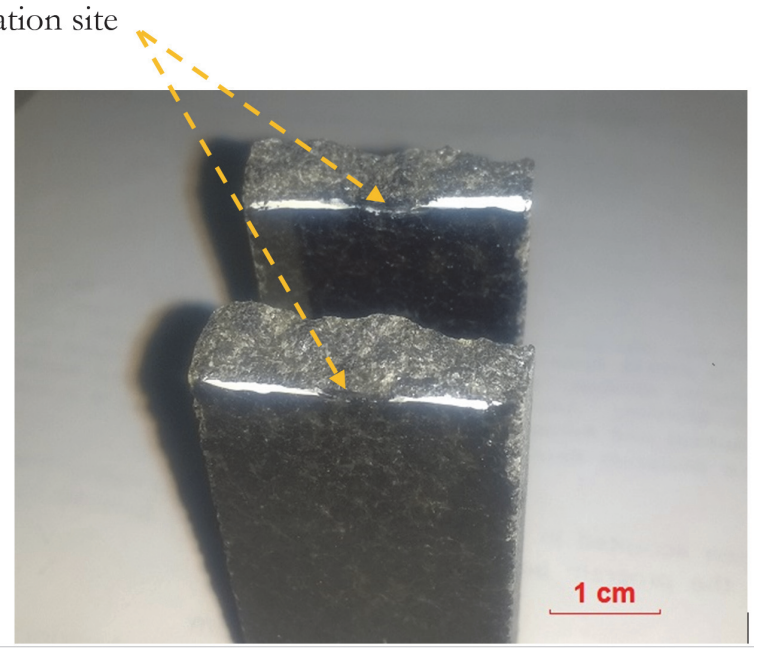

(b)

Figure 6: (a) Fracture surfaces for lower loading (15.5 MPa), (b) Fracture surfaces for higher loading (19 MPa)

The range of load reported in Fig. 4 was not wide: from 15.5 MPa approximately to $19 \mathrm{MPa}$; nevertheless, a clear fatigue endurance tendency is observed from the average experimental points in Fig. 4. Furthermore, the fracture surfaces were different for these two loading level, as shown in Figs. 6(a) and 6(b). For the lower applied load, Fig. 6(a), a quasi-flat fracture surface was observed; whereas for the higher applied load, Fig. 6(b), the fracture surface was irregular, particularly at the applied load zone. In both cases, the crack initiated at the contact zone between the awl and the surface of specimen and propagated firstly along the contact surface and afterwards, across the thickness of the specimen, from the top surface to the bottom surface. The time from crack initiation to crack propagation and failure was close to 15 seconds for the lower applied load (15.5 MPa); whereas this time was reduced to 4 seconds approximately for the higher applied load (19 MPa).

\section{Acoustic Emission (AE) technique}

Crack initiation and propagation in granite is an energy absorption process and an energy dissipation process that may be monitored by thermal and/or acoustic emission (AE), techniques [16-20]. From theoretical point of view, the fundamental equation that govern time to failure for uniaxial tensile in material is [21] : 


$$
\tau=\tau_{0} \exp \left[\left(U_{0}-\gamma \sigma\right) / \mathrm{kT}\right]
$$

where: $\tau$ is the time to failure, $\tau_{0}$ is the period of the natural oscillation of atoms in the solid, $\mathrm{U}_{0}$ is the binding energy on the atomic scale, $\gamma$ is a parameter proportional to the disorientation of the molecular structure, $\mathrm{k}$ is the Boltzmann's constant, and $\mathrm{T}$ the absolute temperature. This equation has been validated for a wide variety of materials such as metals, alloys, nonmetallic crystals, and polymers; nevertheless, when the time to failure is large enough, this equation ignores the reforming of atomic bonds and is not valid [22].

Quasi-brittle materials, including rocks, may fail under subcritical loading [23, 24]. Granite is characterized as coarser-grained crystalline rocks, which fatigue repeatability under three point bending tensile tests is characterized by random variation $[25,26]$; nevertheless, ultrasonic fatigue endurance obtained in this paper for the tested granite specimens shows a typical evolution in the S-N graph, as illustrated in Fig. 4. The repeatability on ultrasonic fatigue results here reported may be associated with the concentrated applied load at the center of the specimen, under this modality of very high frequency and low amplitude loading. The fracture of testing specimen quasi perpendicular to its length, Fig. 6, would be related to such repeatability too.

In order to correlate the temperature variation during testing with the crack initiation and propagation, acoustic emission (AE), tests were carried out. The PAC system 18-bit A/D from MISTRAS Group, with $1 \mathrm{kHz}-3 \mathrm{MHz}$ of scanning frequency was used for this purpose. The calibration for the acoustic emission tests was obtained following a procedure reported in ref. [27].

In Fig. 7 the frequency of elastic shocks recorded by AE (events rate/second) is plotted in the vertical axis against the time of ultrasonic fatigue test, in the horizontal axis. The results shown in this figure correspond to the lower applied load of 15.5 $\mathrm{MPa}$ with a testing time of approximately 16 seconds.

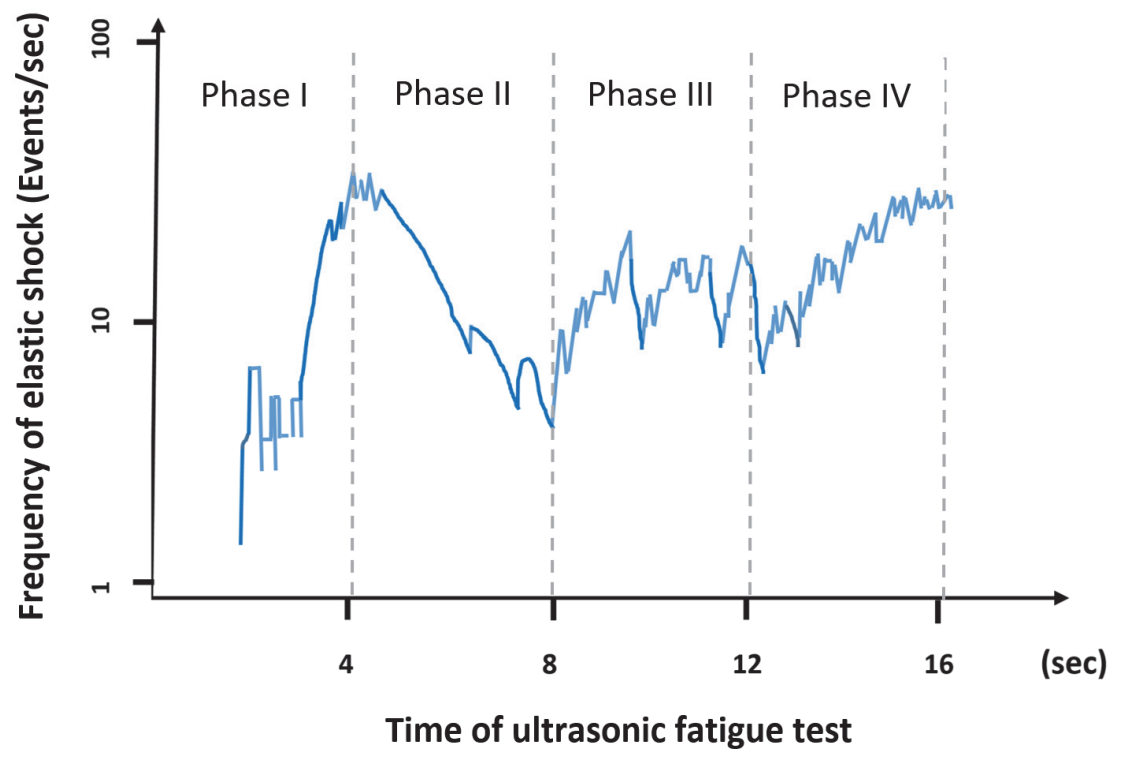

Figure 7: Frequency of elastic shock against time of ultrasonic fatigue life of approximately 16 sec.

Four stages are clearly distinguished during ultrasonic fatigue testing: the first stage, named phase I, is characterized by a noticeably increase of AE immediately after applying the load; the second stage is related to the gradually reduction of event rate (phase II). The third stage (phase III), which begins roughly at half of fatigue life, shows an exponential increase of the event rate, whereas in the last stage (phase IV), an import increase of event rate is observed before fracture. The four described stages during ultrasonic fatigue testing are related to the stages of the temperature on the granite specimen, recorded by the thermographic camera. Temperature increases rapidly at the first stage (phase I of AE), following by a quasisteady state of temperature during the second stage (phase II of AE), and an increase of temperature during the third and fourth stages (phase III and phase IV of AE). Acoustic and thermographic analysis simultaneously may be used to predict the fatigue life of testing specimens [28]. 
This paper is a first attempt of the authors to investigate the relationship between the energy registered by acoustic emission and by thermographic technology [29, 30], related to fatigue behavior under ultrasonic fatigue testing. Further investigation in this field are expected in the next future.

\section{CONCLUSIONS}

he following conclusions may be drawn from the present work:

- Ultrasonic fatigue tests are carried out on the granite rock, under the three point bending;

- Ultrasonic loading is applied by an aluminum awl, which is calculated by finite element method to fit the resonance condition;

- Higher temperature is observed by thermographic images at fracture;

- Ultrasonic fatigue endurance of this granite prism follows the S-N curve in the narrow range of applied load: 15.5 to 19 $\mathrm{MPa}$;

- Fracture surfaces are perpendicular to the axe of specimens and present higher irregularities when the applied load increases;

- Acoustic emission techniques are used to register the events during the ultrasonic fatigue tests on the granite, showing that four stages (phases) are present along the time of testing;

- Acoustic emission and thermographic technology may be used to investigate the endurance under ultrasonic fatigue testing.

\section{ACKNOWLEDGEMENTS}

he authors express their special mention of gratitude to CONACYT (The National Council for Science and Technology, Mexico), for the financial support destined to this study by the program grant: CB- 241117- 2014. An additional mention of gratitude to the University of Michoacán in Mexico, for the received support in the development of this work.

\section{REFERENCES}

[1] Li, H.B., Zhao, J., Li, T.J. (1999). Triaxial compression tests of a granite at different strain rates and confining pressures, Int. J. of Rocks Mech. and Min. Sci., 36(8), pp 1057-1063. DOI: 10.1016/S1365-1609(99)00120-3.

[2] Zhou, T., Dong, S. L., Zhao, G. F., Zhang, R., Wu, S. Y., Zhu, J. B. (2018). An experimental study of fatigue behavior of granite under low-cycle repetitive compressive impacts, Rock Mech. and Rock Eng., 51(10), pp. 3157-3166.

DOI: 10.1007/s00603-018-1515-0.

[3] Basu, A., Mishra, D.A., Roychowdhury, K. (2013). Rock failure modes under uniaxial compression, Brazilian, and point load tests, Bull. of Eng. Geol. and the Env., 72(3-4), pp. 457-475. DOI: 10.1007/s10064-013-0505-4.

[4] Oda, M., Katsube, T., Takemura, T. (2002). Microcrack evolution and brittle failure of Inada granite in triaxial compression tests at $140 \mathrm{MPa}$, J. of Geoph. Res., 107(B10), pp. ECV 9 1-17. DOI: 10.1029/2001JB000272.

[5] Zhao, J., Li, H.B., Wu, M.B., Li, T.J. (1999). Dynamic uniaxial compression tests on a granite, Int. J. of Rocks Mech. and Min. Sci., 36(2), pp. 273-277. DOI: 10.1016/S0148-9062(99)00008-X.

[6] Li, H.B., Zhao, J., Li, T.J. (2000). Micromechanical modelling of the mechanical properties of a granite under dynamic uniaxial compressive loads, Int. J. of Rocks Mech. and Mining Sci., 37(6), pp. 923-935. DOI: 10.1016/S1365-1609(00)00025-3.

[7] Sun, J., Hu, Y.Y. (1997). Time-dependent effects on the tensile strength of saturated granite at Three Gorges Project in China, Int. J. of Rocks Mech. and Min. Sci., 34(3-4), pp. 306.e1-306.e13, DOI: 10.1016/S1365-1609(97)00222-0.

[8] Noor-E-Khuda, S., Albermani, F., Veidt, M. (2017). Flexural strength of weathered granites: Influence of freeze and thaw cycles, Const. and Build. Materials, 156, pp. 891-901. DOI: 10.1016/j.conbuildmat.2017.09.049.

[9] Dai, F., Xia, K. (2010). Loading rate dependence of tensile strength anisotropy of barre granite, Pure and Appl. Geophysics, 167(11), pp. 1419-1432. DOI: 10.1007/s00024-010-0103-3\}. 
[10] Mpalaskas, A.C., Matikas, T.E., Van Hemelrijck, D., Papakitsos, G.S., Aggelis, D.G. (2016). Acoustic emission monitoring of granite under bending and shear loading, Archiv. of Civil and Mech. Eng., 16(3), pp. 313-324.

DOI: $10.1016 /$ j.acme.2016.01.006.

[11] Tarasov, R.G., Randolph, M.F. (2011). Superbrittleness of rocks and earthquake activity, Int. J. of Rocks Mech. and Min. Sci., 48(6), pp. 888-898. DOI: 10.1016/j.ijrmms.2011.06.013.

[12] Friedemann, T.F. (2003). Rocks that crackle and sparkle and glow: strange pre-earthquake phenomena, J. of Scient. Explor., 17(1), pp. 37-71.

[13] Savage, H.M., Marone, Ch. (2008). Potential for earthquake triggering from transient deformations, J. of Geophy. Research, 113, pp. B05302 1-15. DOI: 10.1029/2007JB005277.

[14] Reches. Z., Dewers, T.A. (2005). Gouge formation by dynamic pulverization during earthquake rupture, Earth. and Planetary Sci. Lett., 235(1-2), pp. 361-374, DOI: 10.1016/j.epsl.2005.04.009.

[15] Dominguez Almaraz, G.M., Hernández Sánchez, R., Gutiérrez Martínez, A., Correa Gómez, E., Verduzco Juárez, J.C., López Garza V. (2017) Ultrasonic fatigue tests on the nafion proton exchange membrane, under the modality of three points bending, Proc. Struc. Integ., 3, pp. 571-578. DOI: 10.1016/j.prostr.2017.04.021.

[16] Chen, G., Wang, J., Li, W., Li, T. (2018), Influence of temperature on crack initiation and propagation in granite. Int. J. of Geomech., 18(8), pp. 04018094-1 - 04018094-15. DOI: 10.1061/(ASCE)GM.1943-5622.0001182.

[17] Zhu, D., Jin, H., Yin, Q., Han, G. (2018). Experimental study on the damage of granite by acoustic emission after cyclic heating and cooling with circulating water, Processes, 6, (0101), pp. 1-20. DOI: 10.3390/pr6080101.

[18] Ge, Z., Sun, Q. (2018). Acoustic emission (AE) characteristics of granite after heating and cooling cycles. Eng. Fract. Mech., 200, pp. 418-429. DOI: 10.1016/j.engfracmech.2018.08.011.

[19]Zang, F., Wagner, F.Ch., Stanchits, S., Dresen. G., Andresen, R., Haidekker, M.A. (1998). Source analysis of acoustic emissions in Aue granite cores under symmetric and asymmetric compressive loads. Geoph. J. Int., 135(3), pp. 11131130. DOI: 10.1046/j.1365-246X.1998.00706.x.

[20] Mpalaskas, A.C., Matikas, T.E., Van Hemelrijck, D., Papakitsos, G.S., Aggelis, D.G. (2016). Acoustic emission monitoring of granite under bending and shear loading, Arch. Of Civil and Mech. Eng., 16, pp. 313-324.

DOI: $0.1016 /$ j.acme.2016.01.006.

[21] Zhurkov, S.N. (1984). Kinetic concept of the strength of solids, Int. J. of Fracture, 26(4), pp. $295-307$. DOI: $10.1007 / \mathrm{BF} 00962961$.

[22] Le, J.-L-, Bažant, Z.P., Bazant, M.Z. (2011). Unified nano-mechanics based probabilistic theory of quasibrittle and brittle structures: I. Strength, static crack growth, lifetime and scaling, J. of Mech. and Phys. of Solids, 59(7), pp. 1291-1321. DOI: 10.1016/j.jmps.2011.03.002.

[23] Marji, M.F., Pashapour, A., Gholamnejad, J. (2011). Relationship between fracture dip angle, aperture and fluid flow in the fractured rock masses, J. of Mining and Env., 2(2), pp. 136-145. DOI: 10.22044/jme.2012.65.

[24] Anders, M.H., Laubach, S.E., Scholz, Ch.H. (2014). Microfractures: A review, J. of Struct. Geol., 69(Part B), pp. 377394. DOI: 10.1016/j.jsg.2014.05.011.

[25] Fernau, H.C, Lu, G., Bunger, A.P., Prioul, R.: Aidagulov, G. (2016). Load-rate dependence of rock tensile strength testing: experimental evidence and implications of kinetic fracture theory. In: Proceedings 50th U.S. rock mechanics symposium, Houston, TX, USA, (paper No. 16-369).

[26] Winner, Lu, G., Prioul, R., Aidagulov, G. (2018). Acoustic emission and kinetic fracture theory for time-dependent breakage of granite, Eng. Fract. Mech., 199, pp. 101-113. DOI: 10.1016/j.engfracmech.2018.05.004.

[27] McLaskey, G.C., Lockner, D.A. (2016). Calibrated acoustic emission system records M -3.5 to M -8 events generated on a saw-cut granite sample, Rocks Mech. and Rocks Eng., 49(11), pp. 4527-4536. DOI: 10.1007/s00603-016-1082-1.

[28] La Rosa, G., Clienti, C., Lo Sabio, F. (2014). Fatigue analysis by acoustic emission and thermographic techniques, Proc. Eng., 74, pp. 261-268- DOI: 10.1016/j.proeng.2014.06.259.

[29] Goldammer, M., Sause, M.G.R., Rieger, D. (2016). Combined acoustic emission and thermographic testing of fibre composites, 19thWorld Conference on Non-Destructive Testing 2016, 13 - 17 June 2016 in Munich, Germany, 8 pages.

[30] Aggelis, D., Kordatos, E., Matikas, T. (2011). Monitoring of metal fatigue damage using acoustic emission and thermography, J. of Acous. Emis., 29, pp. 113-122. DOI: 10.1117/12.881021. 